\title{
PROCESANDO LA MODERNIDAD: ANATOMÍA DE UN ¡Y YO QUÉ!
}

POR

\author{
José Fernando Siale Duangany
}

Salir de la propia tierra para vivir en barro lejano puede ser de por sí una suerte de desprendimiento que genere violencia, aun siendo esta violencia coagulada en los intersticios del profundo sentimiento de desarraigo y de la paulatina cicatrización de la herida dejada por el arrancamiento de la raíz. Sobre todo si el punto de vivencia del desarraigo conlleva el descubrimiento, $\mathrm{y}$, ¡cuán doloroso!, proceso de decadencia de todas las ilusiones acumuladas allá en la tierra natal con respecto de la tierra de acogida.

En primer lugar cabe pensar en lo que se entiende básicamente por "modernizar" en Guinea Ecuatorial. De entrada, no tiene nada que ver con las corrientes sociológicas o filosóficas relativas al cambio de las estructuras sociales y de la forma de vida en Europa tras de la revolución industrial. Por aquí se resume esta expresión en lo que se ve, lo que sin más esfuerzo visual ni reflexión entra por los ojos para calafatearse en las emociones exclamativas. A saber: asfalto, vehículos, hormigón armado, cristal, barrillas, etc. Es así que la misma Guinea Ecuatorial autosatisfecha de su situación, muestra de sí los nuevos edificios de cristal y las autovías como indicio de modernidad y de desarrollo; y cuando ciudadanos y viajeros pasan por lo que se ha acordado llamar Malabo-2 (aunque en esto hay debate porque algunos sitúan Malabo-2 en la carretera de la autovía, y otros por la zona del Río Borabecho) se exclaman: ¡qué moderno es! Ser moderno se ha designado así como aquello que se adhiere a la parte externa de un cuerpo, ya sea de un ser vivo como de un espacio vital como la ciudad. En la persona, por lo tanto, el asunto se ha limitado a muy pocas cosas, en particular, ostentar un teléfono móvil (algunos exhiben dos o tres, signo preferido del plusmodernismo) y poseer un vehículo.

Pocos son los ecuatoguineanos que piensan en la modernización o en el desarrollo como un cambio en las personas, como una interiorización de los conceptos relacionados con la libertad, la educación y el proceso de sacar de abajo a las poblaciones más desamparadas. Que lo moderno o el modernismo se conecten necesariamente con un aumento de la calidad de vida social y cultural de los ciudadanos, es algo sobre lo cual se desliza la cuestión. El espejismo del hormigón armado, del asfalto y de los abalorios 
como paradigmas de lo moderno o de lo desarrollado es tal, que las artes, la literatura, la historia, etc., han dejado de llamar la atención en el debate sobre desarrollo y modernidad.

El proceso de "modernización" basado en aquello que resplandece a primera vista, en Guinea Ecuatorial ha conllevado así a un éxodo rural que afectó a una gran masa juvenil. Esta masa, que ha venido a concentrarse en los alrededores de Bata y de Malabo, brota huyendo del sempiterno ciclo de subdesarrollo, pobreza y hambruna, que ha venido caracterizando la vida paisana desde el decaimiento de la producción del café y del cacao, cultivos de exportación que batieron en brecha las otrora culturas endógenas de autoabastecimiento. En sumatoria, son jóvenes que se han creído rajatabla el slogan demagógico del enriquecimiento fácil para todos (porque vieron los edificios y el asfalto por televisión, y también lo dijo el Delegado del Gobierno en su discurso inaugural), llegan imbuidos de una sobredosis de ilusión. Y como aquella demagogia la pronunciaba gente que vivía en las ciudades, el campesino infeliz y sin soneto en su aldea tuvo la certeza de que esa felicidad de la que se le hablaba se localizaba en Bata o en Malabo, al alcance de los intrépidos viajantes, como el que ahora se encontraba ahí en el pueblo, repartiendo latería y jabón. Entonces emigró. Nadie le esperaba (incluso su tío-padre se quedó sorprendido al verle llegar), y no estaban previstas medidas de acompañamiento ni sistemas de acogida para los que abandonaban la campaña en busca del pan urbano, pan crujiente no apto para desdentados, sin embargo algunos arribaban con escorbuto ya crónico.

De esta suerte al llegar, el joven desarraigado solamente encontró espacio en los bordes de la ciudad, porque todo lo bueno estaba ocupado. Se instaló así en esas aristas de filo cortante, en la línea de demarcación donde se amontonan en un galimatías indecible: ríos contaminados, estrechez, desescolarización, hacinamiento, calor, cromatismo, barro, chabolas, alcohol para todos, hambruna para casi todos, mugre a compartir, antros en los que se practica toda clase de compraventa con o sin señal. Esas zonas cuyas características rompen todos los escudos protectores contra la promiscuidad, la indignidad y la exclusión, le plantan cara a cualquiera. Pero el joven llegó y también pensó en plantarle cara a la pobreza. En la única reunión del Consejo de Vecinos a la que asistió, tomó la palabra para expresarse y apuntar que se sentía excluido; pero la voz atronadora y el dedo amenazador del representante de la administración le dejaron clavado en su silla: “itú mismo te has excluido!", le largó a la figura. En un intento por sensibilizar a otros jóvenes dockers del puerto para constituir un grupo sindical (él no lo llamaría sindicato sino asociación de trabajadores) y negociar una mejora de sus condiciones de trabajo como estibadores, la policía cargó contra ellos y él perdió su precario empleo regresando alicaído, y con ansias de algo grave, a la barricada de la periferia donde vive.

Este aparcamiento masivo en las periferias urbanas donde las infraestructuras y los servicios sociales son escasos y de poquísima exigencia y calidad, ha entrañado para el

Revista Iberoamericana, Vol. LXXX, Núms. 248-249, Julio-Diciembre 2014, 1117-1122 
país no solamente un problema de pobreza urbana sino también, y fundamentalmente, uno de juventud: violencia, fractura educacional, delincuencia, alcoholismo, pornografía, prostitución juvenil, y toda una gama de consecuencias como las secuelas físicas y psíquicas resultantes de los abusos a que se puede librar un adolescente desorientado, eso sin contar con los efectos del VIH/SIDA y del desistimiento parental. Ante su soledad frente a su destino, manifiestamente incomodado y desorientado ante el falso dilema de si es un excluido o se ha excluido, el joven emigrante se aparta de los patrones cívicos al rebelarse contra las falsas promesas de riqueza para todos, paz y etcétera; porque siente que se tiene que pelear para consumir, debe agredir para que no allanen su espacio vital, tomar con fuerza para tener, gritar para ser entendido, y esos actos no le dejan en paz, porque la violencia no le deja en paz a nadie, ni al agresor, ni al violador ni al soldado. Esta vez cuando pasa por Malabo-2 ya no le sale la exclamación.

Entre ocaso y amanecer escucha por la radio una canción cuya letra está cargada de significado para él: "La pobreza es una situación, que se cura sólo con el dinero". Entonces empieza por pensar que a lo mejor él no entendió correctamente ese concepto. Porque es aquí cuando y donde descubre que entre él y los ideólogos hubo un diálogo de sordos. Éstos hablaban de la paz como ausencia de guerra, y él pensaba en la paz en el alma, en el corazón, la paz que trae la panza llena y la sonrisa en los labios cuando se tiene algo en qué emplearse.

No cabe duda de que en su situación actual, esos eslóganes electoralistas mal entendidos por los campesinos, empiezan a plantear interrogantes, $\mathrm{y}$, a enfrentar serias dificultades en aquellos emigrantes buscadores de felicidad, redescubridores de la exclusión. El capitalismo salvaje con su corolario consumo frenético y ostentatorio se plantan como paradigmas indescifrables por de momento. En primer lugar, los recién arribados llegan rápidamente a la conclusión de que el éxodo rural impide la ampliación de las oportunidades de los afortunados ya instalados, ya que el reparto deberá darse con un mayor divisor, a saber: los desafortunados, más los excluidos, más los recién llegados. Que aunque la familia y el clan son el centro social en la cultura a la que pertenecen, los encargados de proteger a la familia o al clan muchas veces ya no cumplen con su obligación, o simplemente se llevan la parte de cinco leones. Es ahí donde la cuestión social en torno a la desigualdad toca su punto álgido y cuece una especie de violencia velada que sólo se expresa en círculos intestinales. Y por más que en sus noches de embriaguez el apurado cante con Alex Morris el "no quiero odiar a nadie [...] no sabemos mañana lo que será", en el fondo su corazón late, su tórax bombea rabia, la exclusión le tiene cogido por todas las extremidades. Pues el abismo entre afortunados y desafortunados viene a ser tal que la fractura social deviene inevitable, poniendo seriamente en entredicho la felicidad prometida tanto como la cohesión social. Se genera frustración, codicia, complejos.

A colación se me ocurre un flash de diálogo que mantuve con uno de esos jóvenes, distribuidor de combustible en una estación de servicios de Malabo. Respondió gentilmente

Revista Iberoamericana, Vol. LXXX, Núms. 248-249, Julio-Diciembre 2014, 1117-1122 ISSN 0034-9631 (Impreso) 
a mi saludo, y, mientras me llenaba el tanque, mirando detenidamente el vehículo, me preguntó: “señor, ¿cómo es cuando se vive bien?” Interpelado así de sopetón le devolví la pregunta: ¿Cuando uno está bien con sus hijos, no tiene problemas con los vecinos, ama a su mujer y la mima...? El dependiente no me dejó salir campechanamente por la escapatoria. No, dijo, eso es vivir en tranquilidad, iyo hablo de cuando uno vive bien!...; y esta frase fue pronunciada con cierta entonación.

Se pregunta, entonces, el joven excluido cómo pueden llegar, y por qué atajo, a la riqueza de la que les hablaron en el pueblo, para poder vivir "bien". Alguien dijo acá y allá que en el puerto podían hacerse "affaires", otros comentaron que probablemente lo de llevar taxis a lo loco y como a uno le daba la gana producía efectos agradables, los más jóvenes se pusieron de lava-coches en los alrededores de los supermercados y de los bancos, otros empezaron por crear alianzas poco saludables para la ética pero agradecidamente buenas con el bolsillo, los demás se dedicarían a la estafa "legal" de los extranjeros, un gran-alguien dejó divulgar una larga lista de actividades especialmente diseñadas para gente desescolarizada y para protervos en potencia, entre las que subrayaba el canibalismo administrativo y el agotamiento del Tesoro Público, pero también leyeron en alguna revista que existe además la posibilidad de la manducación del Estado en todos sus desmembramientos. En una tarde de copas, cinco jóvenes como él reconocieron haber robado varios millones de las cuentas de empresas privadas y que el juez no les hizo nada porque supieron "hablar con él". En una vuelta por el barrio de Malabo-2 le enseñaron la casa del que fue juez de Primera Instancia, una mansión, no una chabola cualquiera: una mansión con pilares y watch-man con porra.

De esta suerte, el joven llegado cae inconscientemente en el sueño del círculo vicioso del consumo y de la ostentación, que son a la vez agentes patógenos de la exclusión social y de la violencia, aunque generen a veces y traicioneramente eso que el de la gasolinera llamaba vivir "bien". El destino individual del joven rural se calca privilegiando una identidad superficial que se ha erigido en paradigma, a pesar de su alto grado de reconocimiento social de pacotilla. Pero aun así, en la más de veces el joven inmigrante descubre que esta fachada de naipes, este reconocimiento aun de pacotilla no está al alcance de todos; y el recién venido, sin conocimiento ni medios vertiginosos de acceso a la moneda, y por ende al consumo y a la ostentación, se apropia de la violencia o de la cosificación del sexo y de la desvergüenza como figuras de representación de lo moderno y de acceso a la felicidad reinantes. Su proceso de desarrollo personal se enfrenta así drásticamente con la instantánea de la ostentación. ¿Una porción de un mundo desbocado donde no hay oportunidades loables para todos, salvo las adquisiciones en la oscuridad? ¿Nos abocamos aquí a un proceso de modernidad corroído por el conservadurismo de la administración, anquilosada en muy poco laudables privilegios adquiridos consistentes en el mínimo resultado para el administrado, pero sí un máximo frenesí y acaparamiento para el administrador? ¿Vamos a tener que escoger entre la supervivencia del joven rural emigrado y la manducación del Estado?

Revista Iberoamericana, Vol. LXXX, Núms. 248-249, Julio-Diciembre 2014, 1117-1122 
Aquí es donde el hombre de a pie acepta con rebeldía y desafío que el discurso demagógico, el trabajo, la idolatría política a la que se había ejercido durante tantos años, así como lo que se dice que hay por Malabo y Bata, son un espejismo soberbio, y no un atajo bien asegurado para ser felices ni comer perdices ni vivir bien. Hay que actuar de otro modo. Mira a su alrededor. Se fija detenidamente en las cualidades intrínsecas de algunos afortunados. Aprende a privilegiar el cuerpo al discurso. Y lo comprende sin demasiada gimnasia mental. Entonces arremete contra la ley, la desmiembra como se hace con la tortuga para el envuelto, se acomoda como el centro de la sociedad, lo único y sólo es él, ¡abajo la solidaridad!, su auto-reconocimiento se plasma sobre un defecto de reconocimiento social confundiéndole en un enredo mental.

A la sazón el recurso a los catalizadores mágicos para el reconocimiento y éxito sociales se hace inevitable. Otros posibles atajos para la felicidad se le revelan. Brujería y modernidad entran en un conjunto homogéneo confuso. Pues tanto el concepto de brujería como el de lo moderno son tan elásticos, poco formateados, y prestos a interpretaciones y contenidos tan dispares, que su enlace es casi natural en estas latitudes. Nadie sabe a ciencia cierta lo que encierra lo moderno (aunque algunos afirman que se cuaja en los rascacielos y en el asfalto kilométrico con sus vehículos), nadie sabe a ciencia cierta lo que encierra la brujería (ese colapso mental de violencia incomprendida); y el rural desorientado se apropia de lo que más le resulta familiar para domesticar lo que le es un tinglado de acceso restringido. Los relatos sobre el origen de la fortuna o de la gloria de algunos que llegaron a Bata o a Malabo en chancletas de baño, y que por ahora llevan diez años sin pisar suelo firme de tanto ir en coche, no espantan ya a nadie; pues esta nueva forma de brujería, en contraposición a la clásica, está cautivando cada día más adeptos. Esos hombres son referencia cultural. Devienen en unos bienhechores que apoyan a los equipos deportivos, perforan pozos de agua potable, realizan obras sociales -expresión muy a la moda-, compran chapas de zinc para los que se quedaron en el pueblo. De igual manera pero por otros caminos en los que la confusión entre fe y credulidad son moneda común, el desamparado recurrirá a las religiones de reciente implantación, donde se le prometerá el edén, trabajo en el sector petrolero o en la ingeniería civil, riqueza y matrimonio con mujer pura y casta que le guardará fidelidad hasta que el odio los separe. Soñará con ser como el "pastor", que circula en un tan brillante como espacioso vehículo, come más de cuatro veces al día sin que le afecte la arteriosclerosis, no bebe agua sino champaña, engorda bien, su teléfono móvil tiene saldo eterno; y el emigrado rural vivirá en esta utopía durante varios años.

Pero en la más de veces el joven desarraigado tomará lo que necesita por la fuerza o por el timo. Falsificará documentos, calcará la firma de sus jefes, irá a medias con los de la administración. Pero también se esconderá en los oscuros rincones de la periferia de Malabo y de Bata; agredirá a las adolescentes para quitarles el teléfono, atacará con arma blanca a los transeúntes y les robará el dinero, irá a por los extranjeros a chantajearles

Revista Iberoamericana, Vol. LXXX, Núms. 248-249, Julio-Diciembre 2014, 1117-1122 
su situación irregular o su mera nacionalidad extranjera -que en este paralelo es ya casi un crimen de lesa humanidad-, circulará en su taxi como un desquiciado en busca de pasajeros e insultará con un corte de manga a quien le interrumpa en su libertinaje, aparecerá gritando como un trastornado en el despacho del jefe que le despidió por incompetente, diciendo que "ese blanco no quiere a los guineanos". Y nadie, absolutamente nadie moverá un dedo para frenar la brutal caída de ese joven hacia los limbos de su propia existencia en una inagotable búsqueda del atajo que conduce a vivir bien.

Malabo, Abril de 2010

\section{BibLIOGRAFÍA}

Gil Villa, Fernando. La exclusión social. Barcelona: Ariel Social, 2002.

Mbana, Joaquín. "Brujería fang en Guinea Ecuatorial (El Mbwo)". Sial/Casa de África, 2004

Geschiere, Peter. "Sorcellerie et Modernité: retour sur une étrange complicité. " Afrika Studiecentrum. Politique africaine 70 (octubre 2000).

Comité de Libertad Sindical (OIT). "Derecho de los trabajadores sin ninguna distinción y sin autorización previa de constituir las organizaciones que estimen convenientes". Boletín oficial de la OIT LXXVII/372, Serie B, \# 1 (1994): 121.

Siale Djangany, José Fdo. "Violencia, quiero más". Revista El árbol del Centro 5 (2007).

Revista Iberoamericana, Vol. LXXX, Núms. 248-249, Julio-Diciembre 2014, 1117-1122 